\title{
Erratum to: Freedom Russet-A Dual Purpose Russet Potato Cultivar with Resistance to Common Scab and Good Fry Quality
}

\author{
Horia I. Groza • Bryan D. Bowen • Alvin J. Bussan • \\ Felix M. Navarro • Walt R. Stevenson • Jiwan P. Palta • \\ Jiming Jiang
}

Published online: 5 June 2010

(C) Potato Association of America 2010

\section{Erratum to: Am. J. Pot Res}

DOI 10.1007/s12230-009-9096-9

The text under Fig.1, page 407, should be correctly read: "Pedigree of Freedom Russet. WN12-3 and WN39-1 are selections made by William Hoyman (USDA/ARS) at Washington State University Irrigated Agriculture Research and Extension Center in Prosser, Washington".

The online version of the original article can be found at http://dx.doi. org/10.1007/s12230-009-9096-9.

H. I. Groza • A. J. Bussan • F. M. Navarro • J. P. Palta •

J. Jiang $(\bowtie)$

Department of Horticulture, University of Wisconsin-Madison,

Madison, WI 53706, USA

e-mail: jjiang1@wisc.edu

H. I. Groza • B. D. Bowen • F. M. Navarro

Rhinelander Agricultural Research Station,

University of Wisconsin-Madison,

4181 Camp Bryn Afon Road,

Rhinelander, WI 54501, USA

\section{W. R. Stevenson}

Department of Plant Pathology,

University of Wisconsin-Madison,

Madison, WI 53706, USA 